\title{
The docile body - Reflecting the school
}

\section{Zuzana Bánovčanová, Dana Masaryková}

Abstract: The paper deals with corporeality in the school environment from a historical perspective. The body has tended to appear and disappear in the discourse and scientific disciplines and has permeated education. This permeation can be viewed traditionally within Merleau-Ponty's phenomenological theory of the "lived body" but also in school discipline. Discipline is typically used to organise the school and is unquestionably associated with the body and corporeality. In this article, we therefore rely on Foucault's theories. Docile bodies are typically found in schools and classrooms and are shaped by the institution so that they are easy to manage and control. In part, we demonstrate this using handwriting in schools as an example.

Key words: discipline, Foucault, school, body, education

\section{Introduction}

When considering the body and corporeality in education (from a historical perspective), one has to focus on sport and physical education, since it is in these subjects that the body has gained indisputable importance, especially in Antiquity, the Middle Ages and early Modernity. In this (CzechSlovak) region, theories of the body have also been associated with the establishment of physical education associations. One of the most important figures in this respect was Miroslav Tyrs, who established the Prague Physical Education Association (1862), the forerunner of Sokol Pražský (one of the most famous physical education associations in the region). However, in an era of prevailing cognitivism, the body disappeared from pedagogical discourse. Towards the end of the 20th century the body and corporeality once again began to filter into researchers' awareness, in anthropology, which now provides us with the main theoretical basis for performing research on corporeality in education. 
In this paper we focus on the school environment, where the body (especially that of the pupil) has unique status - functioning as a symbol, from the earliest times to the present day. The body is thus a means of acquiring knowledge and it is also a symbol representing a particular culture, in this case the culture of school. The school as an institution and school culture have typical features, especially discipline, norms, regulations and also rituals which can be seen in the bodies of schoolchildren. In this respect, it is also possible to observe the institution's regulations and disciplinary procedures in pupil-teacher communication through hand raising, but also in learning how to write. When writing in the school environment the pupil's body adopts a particular position. The classroom, the institution's basic (functional and social) unit, also has spatial specifications, which constrain the pupil's body, enabling effective (and also impressive) control not only of the body, but also of the mind.

This approach is based on body discipline, which, in the school environment, is constrained and created spatially (seating arrangements - the desks, the classroom, the arranged rows, double rows, and columns) but also temporally (the timetable, the precise daily breakdown of all activities).

\section{Historical exploration of corporeality in the school environment}

The body is a very broad topic often discussed in classical philosophy and spanning many fields, including education, over the centuries. Corporeality was a topic of discussion back in the eras of Spartan and Ancient education. It has ebbed and flowed throughout history and in education and training has generally concentrated on physical training. In Sparta, especially, education was associated with physical specialisation as preparation for battles and wars. By contrast, Athenian education focused on the harmony between body and soul (Jansa, 2012).

However, in the Middle Ages the moral and spiritual goals of physical education disappeared as it began to focus solely on preparing for battle and war in keeping with the then prevailing model of the knight. In the heroic epics that emerged at that time, the model of knighthood dominated, particularly in the 12th and 13th centuries (Schmidtke, 2008). Apart from knighthood, in the Middle Ages, corporeality was primarily referred to in the context of Christianity, which prevailed across Europe, and the body was subjected to discipline and conveyed submission. In this period, various religious orders also gained prominence, leading to the development of schooling in Europe. However, the history of the Church is associated with a renouncing of the 
human body, which was subjected to an ascetic way of life. It is, however, important to understand that the body is of supreme importance in the Christian world (the Eucharist and the resurrection, for example) and so it would be better not to refer to a complete repudiation or suppression of the body in Christian history and education. For instance, Perutka et al. state that "all education in early Christianity aimed to induce humility and obedience. Therefore schools reinforced discipline and practised corporal punishment" (1988, p. 50). This kind of discipline was also practised physically, in the way the body was positioned in the classroom, that is, the operational positioning of the body, as described by Foucault (2000).

The Ancient traditions were renewed in Modernity with the advent of humanism and the renaissance. Thus, the Ancient traditions also saw new ideas about man and education with the return to the ideal of the unity of body and soul and to the aesthetisation of corporeality (for instance, ballroom dances in the royal courts). Physical discipline, or rather corporal punishment, was discouraged and as society developed, education, along with pedagogical and methodological approaches and techniques, was developed and so disciplinary techniques were modified.

For science and education, however, research conducted in historical anthropology in the 1980s into corporeality, children and young people was crucial. Kamper and Wulf (in Schmidtke, 2008) contributed significantly to the renewed interest in researching the body and corporeality, discussing how the body was subjected to abstraction and rationalities (during work, sport, and in lessons). Over time the dualism of soul and body has been rejected to be replaced by the notion that everything that has an impact on the physical body constructs a psycho-physical body and has an effect on the mind of the individual. Deliberately exerting an impact on the body through pedagogical theories has long been a premise in education (Schmidtke, 2008). Interest in pupils' bodies in school has been on the increase, as seen by Sherer in the aesthetisation and drawing of children's bodies (in art) and also in the continual subjugation and conquering of the child's body within the school as an institution (ibid.).

The body also appeared in a lecture by Marcel Mauss, "Techniques of the Body" (in 1936). He argued that the body "is man's first and most natural instrument. Or more accurately, not to speak of instruments, man's first and most natural technical object, and at the same time technical means, is his body" (Mauss, 1972, p. 96). Thus, via its morphology and physiology, the body restricts the potentiality of culture. Every culture deals with the 
human body in a certain way (such as, hygiene habits, ways of walking, etc.); each culture treats the body in a particular way, adapts it, disciplines it, gives it a particular role, etc.

Mauss understands the techniques of the body to mean "the ways in which from society to society men know how to use their bodies" (Mauss, 1989, p. 199). The body is therefore cultural, or rather, it "mirrors" culture, since the body reflects the ways in which it is treated, and the traditions and the various techniques for using the body. According to Mauss, the body is man's foremost and most natural tool (ibid.) and the use of the body; that is, the tool, is culturally encoded.

The bodies of pupils and teachers are therefore a cultural reflection of the school institution. The way schools shape individuals and how they affect them - referred to as the techniques of the pupil's or teacher's body - are all most evident in school discipline.

\section{The role of the body in education today}

The body is currently gaining importance in institutional learning and communication, and therefore also in shaping the social relations that characterise this century, in which the cognitive domain is once again associated with the body. In teaching, a pupil's body seems to be being constantly guided and corrected, subjected to investigation and observation, which points to the importance of the body not only in the learning process and the acquisition of knowledge, but also in the process of enculturation, shaping relations and integrating bodies.

The same principles apply to pedagogical interaction as they do to other types of social interaction, namely, that the amount of information exchanged is greater if the body is also involved. A repertoire of expressions is to be found in the face and hands, particularly in the school environment. By acquiring and making ritual use of gestures specific to the school environment the child becomes a pupil (Wulf, 1997), and thus learns a different culture - the culture of education and this is also reflected in the techniques of the body.

The learning body is also affected by the way in which the school is organised, i.e. institutionally. Hand raising is one phenomenon found in body ethnography, where particular gestures are adopted thus enabling the child to take on the identity of pupil. Doubek (1998) states that hand raising oc- 
curs after an "unannounced competition" in which hand raising is a way of winning. The pupil who is selected is the winner. Raising one's hand physical expresses the pupil's desire to draw attention to him or herself. Over time pupils learn, through their bodies, that by raising their hands they can gain attention which would otherwise not be directed at them. Teachers therefore find themselves in situations where the chosen pupil cannot in fact answer the question. Indeed, Doubek (1998) refers to the fact that he once witnessed a pupil raising his hand when there was no teacher around. This illustrates the powerful impact physical learning can have. The learning body overlaps with the political body (Sheper-Hughes and Lock, 1987), indicating a degree of submission to the discipline directed at the pupil's body, "controlling" and therefore disciplining the pupil in the Foucauldian sense of politics and disciplining the body.

The body is once more a topic of interest and not only in sociological, ethnographical, anthropological and other research related to education but there is also greater interest in the link between the body and the mind and the way they interact when knowledge, skills, and also attitudes are being acquired. In this respect, the research on embodiment, embodied cognition and enactivism is not our primary concern; rather, we seek to resurrect the topic of disciplining the body and the disciplinary powers of the school as an institution, using as our example pupils learning how to write. The theories of Foucault and Merleau-Ponty will of course be taken into account.

\section{Foucault's docile bodies}

Foucault theorized the body, particularly in a military or medical context and later also in the school context. According to Cheville (2005), Foucault's work has also had a great impact on the theory of embodied cognition, in which "the human body is at once an object of culture and subject of cognition" (ibid., p. 86). One of the reasons Foucault had such an impact on this theory is that he erased the dividing line between exteriority and interiority, enabling researchers to explain the emergence of habitus (something like the habits of the body), the basis for subjective dispositions.

Foucault also contributed to the theory of embodied cognition, which concerns the impact of the environment (and the positioning of the body in its environment) and the impact of ideology which determines the relationship between body and mind, i.e. the body as an object of culture and as exerting a subjective influence on the mind. 
As stated above, school and education underwent various transformations in history, which also resulted in changes in disciplinary techniques. We need not convince ourselves that school is not primarily about discipline; sometimes, it is more about shaping the individual for society than the actual educational content. At this point, however, we are no longer talking about physical discipline as corporal punishment. That has disappeared to be replaced by the fashion for communication, for building child-parent and pupil-teacher relationships. According to Pupala (2004), the use of corporal punishment today evokes feelings of guilt, the powerlessness of authority and a loss of self-control. Corporal punishment and also the way bodies are dealt with in schools are unavoidably connected to the power of the institution. However, we should not view this power nor the way in which bodies are dealt with in the school environment negatively, since both of these are essential in shaping the individual.

Foucault also developed the concept of the body as an "object and target of power" (2000, p. 138). He discusses the body, paying considerable attention to, since it could be (and still can be) controlled. We do not in fact directly see the techniques used in relation to bodies - these days they are hidden deeper in teaching practices, but we can still see them in the ways in which the body is constrained.

The techniques indicate a particular relationship with the bodies of pupils: "The individual body becomes an element that may be placed, moved, articulated on others" (ibid., p. 166). The body is not defined by basic variables, such as physical fitness and strength, but the place it occupies, the interval it spans, its regularity and how it changes position. Foucault (1977) thus arrives at his "docile bodies", which are closely related to the discipline applied in social organisations, using techniques such as "enclosure - the specification of a place heterogeneous to all others and close in upon itself" (p.141) and "partitioning - each individual has his own place, and each place its individual" (p. 143). This is intended to prevent individuals from gathering or wandering off. Another technique is that of "functional sites" (ibid.) - identifying a place where bodies can be monitored. In discipline the basic unit is "rank", i.e. categorisation by age, performance, or behaviour. In the 18th century "rank" was used to place individuals as part of school regulations, and so pupils were allocated to classes, corridors, courses, etc. "Rank" therefore assigned each person a particular role, place and time (ibid.).

Today all pupils are placed in a particular class, where they have their established place and role to be performed at a certain time. The organisation of bodies in an educational space like this results in the general organisa- 
tion of teaching and learning, which is then free from disruptive elements to a great extent. Controlling the pupils is much easier for the teacher since all pupils have their own place and because of the way bodies are organised in the classroom. The school environment is firmly linked to the discipline of schoolchildren. Foucault (2000) saw school bodies as "docile bodies", which reflect techniques of power in general and the power of the school as an organisation. In this regard, the way Foucault perceived the body and corporeality has enormous significance for the way a school is organised. From the perspective of Foucault's theory, the school as an organisation cannot be seen as a place where the cognitive processes can freely develop nor as an institution for educating pupils, but as a place that is characterised by the corporeality of all those involved in the educational process. It is the body that is visible and that is handled and that restricts education by being present in space and time.

The significance of the body in school discipline can also be found in a historical review by Margolis and Fram (2007), which pinpoints aspects of the school as an institution from a historical point of view. They discuss the fact that surveillance, discipline and punishment in schools could and still can be clearly seen on pupils' bodies. The way in which schools shape our bodies through discipline is aptly illustrated by the example they give of Sioux boys, on entering school (ibid., p.201) and three years later. The Sioux boys have clearly changed into young, educated and well-dressed men. The "power of organisation" emerges here as well.

\section{Writing as a school discipline}

In addition to the examples above, we will now focus in what follows on writing as a school subject. We write throughout our schooling without being aware of its physicality or the fact that it is a physical discipline, since it becomes a habit over time. Initially however, learning to write is a physical drill that involves the body in method.

E. Alerby (2009) has attempted to clarify, understand and debate the role of the body in learning how to write and uses the phenomenological theories of Merleau-Ponty's "lived body" to explain the role of the body in order to focus on writing as embodied experience.

According to Merleau-Ponty's theory we acquire our experiences of the world through our body, and these are the basis for learning (and teaching). Alerby (2009) uses Merleau-Ponty's example of the way in which a blind 
person's body is "extended" through the use of a white cane to describe writing, where the pen functions as an "extension" of the pupil's body helping him gain experience of the world - through writing. Children have to learn to hold a pen properly. The first time they hold a pen in their hand it does not form part of their body and so it is important for them to develop the habit, in the sense of habitus as understood by Mauss. It has to lead to "embodied writing", a combination of corporeal elements (the correct sitting position, the position of the body, head and hand, proper pen grip, fine motor control of the hand) and writing itself, a physical act through which we are able to express our internal feelings and knowledge so that they are visible to others. When teaching children how to write, teachers rely on their own experience, i.e. on their habitus, and on what is embodied within it.

Basically, the pen as object must become a subject and must be integrated with the pupil's body. When pupils first hold a pen and want to write something, they focus only on the pen and how to hold it correctly. In this case we cannot talk about habitus. It is later when the child stops focusing on the pen as a foreign object and starts focusing on what he or she wants to say with it that the pen becomes an "extension" of the pupil's body. Thus the pen becomes a subject, i.e. an integrated part of the pupil's body. Every experience a pupil has at school is experienced through the body. A typical instance of physical experience is a pupil listening to and understanding, on the basis of existing knowledge, a series of sounds which he then writes down. Language, speech and writing transcend the whole body, and are therefore physical experiences and are embodied.

Merleau-Ponty's theory is not the only theory relevant to classroom writing in schools and the pupil's body. Similar links to embodied techniques, such as writing, can also be found in the work of Foucault, who refers to a "correlation of the body and gesture" (2000, p. 221). According to Foucault, writing is seen as producing a "docile body", which is governed and controlled through a series of defined movements associated with a particular body posture. Disciplining the body is the basis for writing correctly, correlating movements and the body and correctly handling the implement. As stated above, through "embodied writing", created via particular fine and planned movements, we can express our attitudes and opinions. Nonetheless, Foucault sees this complex correlation between the movements and body positions and the implement not as an expression of our "internal self", but as an expression of our submission to disciplining the body. 
In the theories of Merleau-Ponty and Foucault there is much that is similar for our consideration of the techniques for adopting the correct body posture and holding the implement, and the canonical order the various movements must be performed in for it to represent a habit which must be acquired in order to write. Merleau-Ponty's example of the blind man and his white cane highlights the physical perception, the fact that the body is essential to perception, as are the need to express oneself or others. Foucault highlights body control, discipline and docility, which can be seen in the short series of movements and the way the implement is handled. For Foucault, writing is the correlation of movement and body and so it is rooted in the concept of the "docile body", while the phenomenological view of the body during the act of writing is rooted in the concept of the "lived body".

As mentioned in the introduction, there are rules and limitations in writing and these can be linked to Foucault's "docile body" (2000). In his wellknown Discipline and Punish we encounter "gymnastics" (p. 221) portrayed as the routine the body performs while writing, consisting of the fine and bold movements and body positions required for writing. Thus writing requires a docile body that adopts a particular position: Both legs are placed under the desk, the left hand is loosely placed at the lower edge of an exercise book, some pupils use the palm of the left hand to prop up their chin. The back is pulled up straight and pupils try to hold their heads so they can see the board and exercise book properly (the text in italics is from observation records).

Similar descriptions of the docile body writing can be found in the illustrated appendix in Foucault's book (2000, Figs. 8 and 10). It is only when the body is constrained and docile that it can perform best, bearing in mind the pupil's health. In any classroom a teacher will warn pupils - Backs straight, heads up! I can see you slouching, you won't be able to write neatly. - as Foucault (p. 222) said, a "well-disciplined body forms the operational context of the slightest gesture". Apart from the posture and position of the body when writing, there is also the manoeuvring of the instrument - the pen (Alerby, 2009 and Merleau-Ponty, 1966 an "extension" of the body), which Foucault argues represents the "instrumental coding of the body" (2000, p. 222), requiring fine motor skills when using the instrument, in this case, the pen. In a Slovak school, we saw poetry being used as a learning aid and motivation for adopting the correct body posture, where conversely it was not the body/movement that prompted memorisation or acquisition of the cognitive structure, but verbal stimulation that produced a physical change - the adoption of the correct posture. 
Correctly I sit,

Pencil I grip,

Head held nicely,

I make sure to check.

While reciting the rhyme, all the children performed the movements in the rhyme. Sitting correctly - body posture and position - all conjure up images of neat handwriting.

\section{"Embodied" writing}

Writing is important because it is a means of human communication and of sharing information and culture. Writing is necessary if the child is to continue his or her schooling. Pupils first begin to learn to write in the first year of schooling in Slovakia. Although writing is primarily about acquiring sensorimotor skills, it is related to thinking and the spoken language. Perception, thinking, paying attention and memory all overlap with the physical side when the child is writing.

Embodied writing, as we call it, is based on the experiences of the body- in the sense that Alerby considers writing (2009). Writing begins with physical discipline that worked in the past just as it does today. Starting to write does not simply mean picking up a pen or colouring pencil, but also adopting the correct posture. Pupils' bodies are mainly constrained by the space and the way the classroom is arranged (Foucault, 2000). The only available space for the child to perform certain activities, in this case writing, is provided by the desks and chairs. Another spatial constraint is found in the way the exercise book is laid out. Pupils' exercise books are lined in such a way as to determine exactly the size and arrangement of upper and lower case letters. The constraints in handwriting exercise books mean that the pupils become accustomed to the specific proportions required for upper and lower case letters and over time these will become embodied in the pupils' minds. Following use of these handwriting exercise books, pupils often produce neat handwriting in exercise books without guide lines. It is as if the restricted space in which lower and upper case letters can be produced has become embodied, creating body habits within clearly established rules, which cannot be broken or changed despite the fact that there are no guide lines in the exercise book.

However, before pupils start writing in the handwriting exercise books, they have to acquire the shape of the letters - physically - by repeatedly tracing the shape of the letter in the air with their finger. A very similar 
activity is performed in the handwriting exercise book, where the letter " $\mathrm{K}$ " is written and pupils have to copy the letter at least five times before they start writing on their own. As one teacher said "the children need to get their hand on it". Initially pupils only "see" the final result of their writing in their mind and it is only once there is correlation between the movements and the body (Foucault, 2000), in perfect mimetic imitation of the teacher, that the children can use a pen to write the letter in the exercise book. This physical representation of the letter and simultaneous abstract idea of the symbol is embodiment - the linking of the corporeal representation and the cognitive process/abstract notion of the symbol. Mimetic imitation or learning refers to a productive process, "connected to the body, establishing the link between the individual and the world as well as other people, creating practical knowledge..." (Wulf, 2008, p. 56). According to Wulf $(2004,2005)$ mimetic learning is fundamental to learning and education. Mimetic learning is not simply imitation in order to repeat a gesture, movement or other representation. When the pupils repeat the letters the teacher writes in the air, they are not just imitating the movement. In part, this physical representation also takes place at the cognitive level; the pupils have to link what they have seen (for example the letter $\mathrm{K}$ written on the board) with the movement made by the teacher's hand, which they then need to transfer to their own body. The image the teacher shows them by hand is mirrored. Based on previous physical experience they need to alter it according to the angle from which they see it.

This first "writing in the air" is simply a mimetic process that gives the pupils room to make mistakes. In order to control one's movements, all one requires is self-control over the body. There are no constraints imposed by space, lines or the exercise book. As Wulf (2008) stated: "in a child's world it is not only pictures but also sounds, tastes and tactile experiences that are important" (p. 59). Engaging the body in the mimetic process creates potential for new structures. Pupils discover that they can use their bodies to symbolically interpret a story or event. "Mimetic movement is a bridge between the child and the outside world" (ibid., p. 60). The pupils' mimetic imitations of the writing movements performed by the teacher are not simply repetitions. In the process the pupils create a cognitive structure enriched by their own physical experiences and limited by their physical capabilities. The teacher, therefore, cannot get all the children to produce the same neat handwriting. The aim of this article is to point out that learning the technique of handwriting, unchanged for centuries and based on the disciplining of the body, is grounding for gaining control over movement, fine motor skills and later also writing. 
We also describe a "physical drill" - copying letters into an exercise book and writing in the air with a finger, which clearly indicate physical mimetic learning, the acquisition of habit, the habitus of the body associated with learning not only movements and shapes, but also the methods and rules for writing.

The aim of this physical method is to create a "sensorimotor memory" in the body (children need to get their hand on it), which automatically creates a link between abstraction, the cognitive process and the physical movements. Similar socio-cultural placement of embodiment is represented by the docile body, a body which is not so strictly required at home as it is in the school environment. The concept of writing, neat handwriting in children is related to the correct sitting position and the correct body posture, which is reflected in classroom environment and thus in the culture of the school institution.

\section{Conclusion}

School is where individuals are shaped using a variety of powers and methods. We briefly gave a historical overview of the body in different kinds of scientific research that are also relevant to pedagogy. Both in the past and today we can see the power the organization has in shaping, changing and transforming us in line with a particular image. Although all schoolchildren are individuals, they are part of the image the school institution seeks to create. Being a pupil means not only having to acquire particular kinds of knowledge and skills, but also having to acquire the image of the pupil's body. This image of the body is visible from the outside, not in the morphology or physiology of the body, but in the situations and approaches required by school.

Discipline is manifest in the pupils' bodies for the whole of their school life. The consequences often remain and develop in the individual's working environment. What is particularly visible is the disciplined and docile school body that is not only constrained by space and time and physical positioning. The various teaching methods also "use" pupils bodies in helping them acquire the curriculum and patterns.

Learning to write and, later writing itself, are not intended as physical practices, they are designed to develop fine motor skills and the cognitive abilities of the pupil. Practising writing involves physical regulation, drills, the pupil's mimetic approach, which come together perfectly to create what 
we call the docile body. However, as we have shown this essential learning process is not only about linking the shaping of movements. When writing, the position of the body and the correlation between hand, body and space create the docile body. In the classroom we also observed social aspects, some of which belong to the discipline of anthropology. After all, what other image of the pupil - the pupil writing- could be more characteristic of the school environment throughout the entire history of schooling.

Both theories - Merleau-Ponty's "lived body" and Foucault's "docile body" - show that the body is essential for the individual's perception and formation. In any teaching method there is a certain amount of body interaction and body disciplining.

\section{References}

Alerby, E. (2009). Knowledge as a 'Body Run': Learning of Writing as Embodied Experience in Accordance with Merleau-Ponty's Theory of the Lived Body. Indo-Pacific Journal of Phenomenology, 9 (1), 1-8.

Cheville, J. (2005). Confronting the problem of embodiment. International Journal of Qualitative Studies in Education, 18 (1), 85-107.

Doubek, D. (1998). Pravý život s přiklady ze třetí třídy. Pražská skupina školni etnografie. 3. trída: príloha závérečné zprávy o rešeni grantového projektu GA C̆R 406/94/1417 "Žák v měnicich se podminkách současné školy". [online]. Praha : Pedagogická fakulta Univerzity Karlovy. Website : http://userweb.pedf.cuni.cz/kpsp/ etnografie/frame.htm

Foucault, M. (1977). Discipline and Punish: The Birth of the Prison. Translated by Alan Sheridan, London: Allen Lane, Penguin.

Foucault, M. (2000). Dozerat' a trestat'. Zrod väzenia. Bratislava : Kalligram.

Jansa, P. et al. (2012). Pedagogika sportu. Praha : Karolinum.

Margolis, E., \& Fram, S. (2007). Caught Napping: Images of Surveillance, Discipline and Punishment on the Body of the Schoolchild. History of Education, 36 (2), 191-211. Mauss, M. (1972). Soziologie und Anthropologie. Band II. München : Carl Hansen Verlag.

Mauss, M. (1989). Die Techniken des Körpers. In: M., Mauss (Ed.) Soziologie und Anthropologie, Bd. 2. (pp. 199-220). Frankfurt am Main : Fischer.

Merleau-Ponty, M. (1966/1974). Phänomenologie der Wahrnehmung. 2. Aufl. Berlin: Walter de Gruyter.

Perútka, J. et al. (1988). Dejiny telesnej kultúry. 2. vydanie. Bratislava: SPN.

Pupala, B. (2004). Narcis vo výchove. Bratislava : VEDA.

Schmidtke, A. (2008). Körper und Erziehung in historischer Perspektive: Theorien, Befunde, und methodische Zugänge - ein Forschungsüberblick. [online]. Göttingen: Pädagogisches Seminar der Georg-August-Universität. Website: http://dx.doi. org/10.3249/webdoc-1723

Sheper-Hughes, N., \& Lock, M. (1987). The Mindful Body: a Prolegomenon to Future Work in Medical Anthropology. Medical Anthropology Quarterly, 1 (1), 6-41. 
Wulf, Ch. (1997). Geste. In: Ch., Wulf, (Ed.) Vom Menschen. Handbuch Historische Anthropologie. (pp.516-524). Weinheim/Basel: Beltz.

Wulf, Ch. (2004). Anthropologie. Geschichte, Kultur, Philosophie. Reinbek: Rowohlt.

Wulf, Ch. (2005). Zur Genese des Sozialen. Mimesis, Performativität. Ritual. Bielfeld: Transcript.

Wulf, Ch. (2008). Rituale im Grundschulalter: Performativität, Mimesis und Interkulturalität. Zeitschrift für Erziehungswissenschaft, 1 (8), 67-83.

\section{Authors:}

Zuzana Bánovčanová, Ph.D.

Trnava University

Faculty of Education

Department of School Pedagogy

Premyslená 4

91843

Trnava

Slovakia

email: zuzana.banovcanova@truni.sk

Dana Masaryková, Ph.D.

Trnava University

Faculty of Education

Department of School Pedagogy

Premyslená 4

91843

Trnava

Slovakia

email: dana.masarykova@truni.sk 